\title{
TRABALHO INFORMAL EM TEMPOS “GLOBALIZACIONISTAS”
}

\author{
Ana Elizabeth Santos Alves - UESB ${ }^{1}$ \\ e-mail: ana_alves183@hotmail.com \\ José Rubens Mascarenhas de Almeida - UESB ${ }^{2}$ \\ e-mail: joserubensmascarenhas@yahoo.com.br \\ Por acaso, será honesto, a cada crise, deixar \\ morrer à míngua os trabalhadores, para \\ salvar os dividendos dos acionistas? ${ }^{3}$
}

Émile Zola

\section{RESUMO:}

O objetivo do artigo é refletir sobre o trabalho informal e a sua funcionalidade para a acumulação do capital. Para ilustrar as análises destaca a feira livre, presente nas zonas urbanas das cidades, como exemplo de espaço que estampa de forma bem evidente a precarização do trabalho, o desemprego "oculto" e o comércio. Além disso, o texto mostra que a realidade do trabalho informal é um fenômeno que se planetariza e avança para os países centrais do capitalismo. Busca analisar essas questões a partir de discussões pontuais a respeito da flexibilização do trabalho, do neoliberalismo e da empregabilidade.

Palavras-chave: Trabalho informal. Reestruturação Produtiva. Flexibilização. Globalização. Transnacionalização.

\section{INFORMAL WORK IN TIMES "GLOBALIZATION"}

\begin{abstract}
:
This article aims at reflecting on the informal work and its functionality for capital accumulation. In order to illustrate the analyses, it features the free market, present in the urban areas of cities, as an example of a space which shows in a well evident way the precarization of work, the "hidden" unemployment and the commerce. Besides, the text shows that the reality of the informal work is a phenomenon which mondializes itself and goes onto the central capitalist countries. It deals with analyzing these matters from punctual discussions about the flexibilization of work, of neoliberalism and employability
\end{abstract} Key-words: Informal work. Productive Reorganization. Flexibility. Globalization. Transnationalization.

No Brasil, é visível nas cidades a presença de um grande número de pessoas ocupadas em atividades precárias, por conta própria ou emprego assalariado sem carteira, longe de quaisquer vínculos empregatícios formalizados e direitos trabalhistas. São trabalhadores que lançam mão de diferentes tipos de artifícios individuais para assegurar a sobrevivência. $\mathrm{O}$ espaço público onde essas relações podem ser detectadas num alto grau e variedade é a feira livre na organização das cidades. A feira é um lugar de comércio e sociabilidade que ajuda manter viva a cultura local, as tradições e as crenças. "Feira significa festa" (SATO, 2007, p.4), e festa expressa manifestação cultural (na acepção ampla da palavra). Além desse lado bucólico, comum a todo centro urbano, a feira é também um lugar onde mostra uma diversidade de aspectos da realidade material da sociedade como um todo. 
Assim entendendo, na atual conjuntura, as feiras estampam a precarização do trabalho, o desemprego "oculto" e o comércio, inclusive de produtos contrabandeados. Como mercado de trabalho, a feira organiza-se em rede de relações sociais, na qual se misturam diferentes formas alternativas de ocupação: quitandas de propriedade de feirantes, vendendo todo o tipo de produto (alimentos, roupas, utensílios domésticos, remédios, objetos religiosos, etc.) e explorando mão-de-obra barata; ambulantes (vendedores de refrigerante, de lanches, de rifas, de CDs e DVDs); estivadores (homens e meninos), barracas de camelôs, etc.

Ao caminharmos pela feira livre da nossa cidade $^{4}$, visualizamos a venda de variados tipos de produtos, misturados a mercadorias right tech, dividindo o mesmo espaço mercantil, convenientemente chamado pelos feirantes e pela população de "Feira do Paraguai". Apesar de todos os discursos monofônicos dos meios de comunicação afiliados ao grande capital e das retóricas "pós-modernosas", veiculados com veemência religiosa, o que se observa é consequiência da lógica daquilo que, historicamente, se convencionou chamar de modernidade: miscelâneas expostas em locais precários, próximo a um receptor de lixo, rodeado de humanos que se confundem com urubus (sobreviventes dos detritos a fuçar seu almoço) e de carroças puxadas por burros, utilizadas como meio de transporte de pequenas cargas (informam que foram incorporadas, como há cem anos, aos projetos de saneamento básico: são coletoras de lixo na periferia desta cidade "globalizada"); vêem-se produtos de primeiras necessidades (frutas, verduras, cereais...), produzidos sob um regime semelhante ao de quinhentos anos atrás, o plantation ${ }^{5}$, sob bases análogas às da exploração que marcou o período colonial, mas que, nos anos 1990, foi batizado com a pomposa terminologia de agrobusiness; contempla-se a cultura pasteurizada nas bancas de camelôs, produção em série (cor, tema, padrão, estilo, sons, imagens...) em produtos piratas vendidos a céu aberto. São os filhos-frutos da racionalidade capitalista neoliberal: trabalhadores informais, precarizados, subempregados e desempregados, que ocupam o seu lugar nesse mundo "globalizado", cuja definição remete a simetrias existentes somente no mundo virtual e na retórica neoliberal das velhas e novas direitas políticas.

A visão concreta que se tem diante dos olhos testemunha relações características de várias etapas da história da humanidade, a se entrecruzarem num microcosmo sóciogeoeconômico cuja conformação é contundentemente disforme. Relações tão antigas quanto o comércio e o mercado e tão modernas (no sentido histórico) quanto a financeirização econômica, o trabalho social precarizado e a guerra. Tão paradoxalmente contemporâneas e modernas quanto as maravilhas tecnológicas de última geração, fabricadas made in China ou Taiwan, com trabalho semi-escravo: transações comerciais, creditícias e financeiras, consumo, lucro, especulação, precarização, pirataria, corrupção, picaretagem... E mercadorias: ingredientes indispensáveis à acumulação, reprodução, ${ }^{6}$ concentração ${ }^{7}$ e centralização capitalistas global. Muito do que se vê antecedeu à modernidade e, parte é constitutivo dela - principalmente nos aspectos que dizem respeito ao imperialismo, por mais que os meios de comunicação, políticos e acadêmicos ‘informem' (como é o caso de Hardt \& Negri, 2001), não se tratar disto, mas de um irreversível processo de "globalização" que está ao nosso redor, em nossa casa, em nosso trabalho, em nosso cotidiano.

No Brasil, a realidade do trabalho precário e informal não é nova. Sempre existiu um contingente numeroso de trabalhadores fora do mercado formal de trabalho, sem nenhuma garantia trabalhista. As atividades desenvolvidas por esse grupo de trabalhadores já eram estudadas nos anos 60 e 70 como próprias de países "subdesenvolvidos". A formação de um mundo do trabalho nos moldes clássicos sempre conviveu ao lado de uma mão-de-obra "desqualificada", trabalhando na informalidade. Estudos (BORGES, 2003; 
SILVA, 2002) mostram a convivência de um "núcleo duro" estruturado do mercado de trabalho, formado por postos de trabalho e trabalhadores assalariados, ao lado de um "segmento não-estruturado", composto por trabalhadores informais, analfabetos ou de baixo nível de escolaridade; fenômeno presente nas economias capitalistas da periferia do sistema. As explicações desses estudos giravam em torno da subutilização estrutural da capacidade de trabalho do "segmento não-estruturado", como derivado do acelerado crescimento dos centros urbanos e da migração da população rural, com conseqüente ampliação das favelas, das atividades informais e da violência urbana, condenando esses trabalhadores a uma situação de subemprego ou desemprego oculto.

Por outro ângulo, em uma abordagem marxista, pressupostos afirmam a funcionalidade das formas "alternativas" de organização da produção (segmento nãoestruturado) e exploração do trabalho para a acumulação do capital, na medida em que o "exército industrial de reserva" cumpre o papel do rebaixamento dos custos de produção da força de trabalho. Nesse sentido, Oliveira (2006, p. 135) justifica o papel do "exército de reserva" nos centros urbanos, ocupando atividades informais, como derivado da "relação entre as formas de subsistência e o setor mais avançado do capital", quando explica o desenvolvimento capitalista pós-anos 1930 e a sua relação com o processo de acumulação. Até os anos 80, essas atividades eram caracterizadas como parte do subdesenvolvimento e poderia ser uma situação transitória para a formalização completa das relações salariais. O trabalho assalariado tendia a se generalizar como forma de produção da riqueza.

$\mathrm{Na}$ atualidade, conforme observa Oliveira, as formas atuais de contratação de mãode-obra se distanciam da formalização completa das relações salariais, abrindo espaço para o crescimento do trabalho informal a partir de uma suposta flexibilidade das relações de trabalho, a exemplo das formas de terceirização (versão modernizada da subcontratação). Com as inovações técnico-organizacionais e o aprofundamento da transnacionalização das relações capitalistas, o trabalho informal se amplia e assume novas formas. A desregulamentação das relações contratuais no mercado de trabalho contribuiu para o aumento da insegurança no emprego e eliminação de postos de trabalho. As empresas passam a reduzir o quadro de trabalhadores do chamado "núcleo duro", contratando uma força de trabalho temporária e autônoma.

Enquanto observamos a realidade do trabalho precário, a cada dia que passa se ampliando no Brasil, a literatura vem apontando o avanço sistemático dessa condição nos países desenvolvidos como um fenômeno que se globaliza, em que pese às especificidades de cada lugar, a exemplo das análises elaboradas por Hirata e Preteceille (2002), demonstrando o crescimento do trabalho "flexível" e precarizado na França e no Japão. Aproximadamente, um terço dos trabalhadores no mundo "ou se encontra exercendo trabalhos parciais, precários, temporários, ou já vivenciava a barbárie do desemprego. Mais de um bilhão de homens e de mulheres padecem as vicissitudes do trabalho precarizado, instável, temporário, terceirizado". (ANTUNES, 2007, p.13).

As transformações ocorridas em âmbito mundial no final do século XX, no plano econômico, político e social, afetaram o modo de vida e de trabalho de milhões de pessoas. Presenciamos a "globalização" da lógica financeira, reestruturação produtiva no setor industrial e de serviços, transformações geográficas da produção e das formas de gestão, outra maneira de pensar o lugar do sujeito na organização. Um novo entendimento do "espaço-tempo", caracterizado pela rapidez, "efemeridade e descartabilidade sem limites de tudo o que se produz e, principalmente, dos que produzem: os homens e mulheres que vivem do trabalho" (THÉBAUD-MONY e DRUCK, 2007, p. 26).

A forma desse novo modo de vida e de trabalho, ou seja, um conjunto de mudanças que se apóia na "flexibilização" dos processos de trabalho, dos mercados de trabalho, dos 
produtos e padrões de consumo, encontra explicações na tese da "acumulação flexível" de Harvey (1993) e no modelo de gestão japonês. As empresas que, até então, se baseavam em modelos de gestão fordistas, são levadas a se mobilizarem para ganhar espaço no mercado competitivo com a adoção de novas formas de organização do trabalho. Surge, então, daí, formas industriais totalmente inovadoras, ou são encontradas formas de integrar a produção fordista a uma rede de subcontratação da força de trabalho, objetivando dar uma maior flexibilidade à organização, potencializando o desemprego estrutural, ao destruir/reconstruir os meios de trabalho através de "novas-velhas" formas de precarização.

Desde os anos 70 até a atualidade, o que caracterizou o mundo foi o encontro entre a bonança econômica do capitalismo do pós-II Guerra e a crise estrutural que eclodiu contundentemente e que se mostraria de longa duração. Encontram-se, simultaneamente, nessa fase do desenvolvimento capitalista, expansão (aumento da mobilidade geográfica do capitalismo, procedimento associado a mudanças na organização dos processos de produção e troca) e estagnação, com destaque para a quebra dos acordos de Bretton Woods $^{8}$, para a crise monetária ${ }^{9}$ e energética, para a gênese e engendramento das políticas neoliberais na periferia e no centro do sistema. Na América Latina, consolida-se o predomínio do modelo industrial, marcado por uma interdependência no contexto do imperialismo pós-II Guerra, e evidenciam-se, definitivamente, os limites estruturais do Estado democrático-burguês; uma acentuada queda nos excedentes da produção apontou para um decréscimo na capacidade estatal de atendimento das demandas sociais das camadas médias e populares dos países da região; radicalizam-se as políticas estatais de recomposição capitalista - papel destacado para a reestruturação produtiva.

Nesse contexto, o "novo" tipo de trabalho é baseado na polivalência e multifuncionalidade do trabalhador, na produção "flexibilizada", inspirada no modelo japonês. A ideologia se apóia no discurso de formação de um "novo perfil do trabalhador" flexível e criativo. A lógica é traçada à luz do conceito de "empregabilidade". Cada indivíduo é responsável por se dotar de estratégias de negociação de suas capacidades de trabalho. É a busca do imediato e a valorização do fetiche do sucesso como resultado do esforço individual, num cenário marcado pela falta de emprego. São fundamentos de uma lógica de recomposição capitalista que se denomina de neoliberal.

O neoliberalismo é mais um movimento de internacionalização capitalista, levado a cabo pela fração financeira da burguesia, instalada nos aparelhos de Estado, subordinado às grandes corporações transnacionais, gigantescas associações monopolistas. Trata-se de um fenômeno circunscrito, do ponto de vista histórico, ao fim da II Guerra Mundial; da ótica econômico-financeira, como de recomposição sistêmica; e da esfera político-militar, como de transição de um mundo multipolar para uma conformação unipolar - passando por uma configuração bipolar (EUA/URSS), desde a segunda década do século XX até o fim da Guerra Fria. Nesse contexto, registra-se uma crise mais geral no seio do capitalismo, evidenciada desde o início dos anos 1970, que acabou impelindo o sistema a forjar uma reestruturação tipificada nas adequações econômicas das políticas neoliberais, sem que seus ajustes estruturais ${ }^{10}$ implicassem, tanto nas sociedades de economias periféricas quanto nas centrais, uma ruptura em sua inter-relação e na relação com os centros capitalistas.

No Brasil, a reestruturação produtiva desenvolveu-se no final da década de 80 , tendo como pano de fundo as políticas neoliberais, essencial instrumento para levar adiante a desregulamentação da atividade econômica do capital, exaltando o mercado como única garantia de liberdade da sociedade. As inovações na organização do processo de trabalho aconteceram de forma mais acentuada na esfera da gestão organizacional inspirada no modelo japonês, mais do que nas inovações tecnológicas. As empresas enxugaram o 
quadro de empregados (tanto de operários quanto de executivos) e reduziram os níveis hierárquicos. Com a diminuição do quadro de pessoal, elas passaram a buscar novas formas de se tornarem mais flexíveis e competitivas, passando a exigir dos trabalhadores que continuaram empregados maior responsabilidade e participação no conjunto dos objetivos e métodos da organização. A lógica da 'flexibilização' e desregulamentação do mercado mostrou, na prática, seu objetivo de reduzir os custos do trabalho pelo enxugamento dos quadros de pessoal, utilizando-se da mão-de-obra de operários com vínculos empregatícios precários, trabalho autônomo, por tarefa, estágios e trabalho domiciliar, inserindo transformações gerenciais e Programas de Qualidade Total.

A aplicação das políticas econômicas neoliberais efetuou mudanças significativas nos aspectos jurídicos das relações de trabalho, dando garantias legais às empresas para admitir e demitir trabalhadores de acordo com os seus interesses. Entre as principais modificações no plano dos contratos estão, conforme Thébaud-Mony e Druck (2003, p.41):

o novo Contrato de trabalho por Tempo Determinado (1998); o novo Contrato de Trabalho em Tempo Parcial (1998); o novo Contato de Aprendizagem (2000); ampliação do uso do Trabalho temporário (1974), que generalizou a sua utilização através de portaria (1996); a ampliação do uso do Trabalho Estágio (1999), já utilizado desde 1977, e a lei que possibilita às empresas a contratação de cooperativas profissionais ou de prestação de serviços (1994), (...) a quebra de estabilidade do funcionalismo público.

No setor bancário, por exemplo, a redução dos postos de trabalho é visível. Entre março e dezembro de 1986, foram reduzidos 109 mil postos; entre 1994 e 1996, com a implantação do Plano Real, reduziram-se 161 mil postos no setor (DIEESE, 2001, p.18). A automação constituiu-se outro fator para redução dos empregos, já que a introdução de novas tecnologias eliminou um grande número de tarefas que fazia parte do processo de trabalho no setor. Várias atividades que, originalmente, eram desenvolvidas por bancários agora são executadas por pessoas de empresas contratadas (ALVES, 2005, p 127).

O processo de seleção de funcionários pelos Programas de Demissão Voluntária (PDV`s) demonstrou a nova realidade organizacional dos bancos públicos, que, por um lado, procuraram reduzir o número de trabalhadores estáveis com maior tempo de serviço e maiores salários e, por outro, contratou serviços de trabalhadores terceirizados, sem a garantia do emprego. Os PDV's e a adoção de normas regulamentares que autorizam os gerentes gerais a demitirem, complementam o controle da mão-de-obra num momento em que vem aumentando no mercado de trabalho os índices de desemprego, inclusive para o pessoal mais qualificado.

Sennett (1999, p.110-112) ressalta que, nos programas de reengenharia das empresas, os grupos de trabalhadores mais velhos são candidatos fáceis à demissão, por várias razões como: a flexibilidade é sinônima de juventude, rigidez e agilidade; os funcionários mais experientes tendem a ser mais questionadores; o conhecimento acumulado deixa de ter valor se a empresa está em processo de mudanças; "a flexibilidade dos mais jovens os torna mais maleáveis tanto em termos de assumir riscos quanto de submissão imediata"; os funcionários mais experientes estão perdendo o emprego para quem está disposto a fazer o mesmo trabalho por um salário mais baixo.

Essa lógica levou muitos 'filhos' dos PDV's e desempregados estruturais do sistema a manterem sua sobrevivência por meio da desobediência civil à legislação $\left(\right.$ pirataria $^{11}$ ), promovida pelos interesses daqueles que detêm a maioria das patentes das tecnologias de ponta, ou seja, pelos donos do capital monopolista. Testemunha-se a 
violência que campeia todas essas relações, atestando que também ela é um tenebroso e antigo agente econômico a serviço da acumulação.

Campanhas de demissão negociada diretamente entre empregadores e empregados em vias de exoneração são levadas a cabo na América Latina desde os anos 1980. Sua aplicação veio acompanhada da retórica da "Empresa de Responsabilidade Social" e do sonho neoliberal alimentado pela fábula de que qualquer pessoa podia ser dona do seu próprio negócio. Lima (2006, p.303) ao discutir o trabalho informal na atualidade, chamando-o do "novo informal", lembra a relação tênue entre "flexibilização do trabalho" e precarização, nos tempos de "globalização" ou de aprofundamento da transnacionalização das relações capitalistas. Observa-se o trabalho informal, histórico sinônimo de precariedade, percebido agora também em sua positividade como trabalho flexível, através do conceito de empreendedorismo, em contraposição aos limites do trabalho assalariado. O "novo informal" passa a ser analisado como alternativa ao desemprego estrutural e como uma saída individual para os trabalhadores com maior nível de qualificação e escolaridade. Essa realidade pode ser visualizada nos "novos contratos atípicos" de trabalho, segundo o autor, evidenciado, por exemplo, na ampliação dos grupos de trabalhadores que exercem atividades nos serviços de informática e atuam fora de qualquer formalidade, convivendo ao lado das antigas modalidades do trabalho informal.

O sentido positivo da ampliação de formas mais flexíveis de trabalho, aliado à desregulamentação de direitos trabalhistas, alimentou o discurso ideológico do "empreendedorismo", generalizando a mística de que todo indivíduo pode se tornar "patrão" pelo seu próprio esforço, como alternativa ao desemprego, ao lado do conceito de empregabilidade, definida como o caminho para a saída do desemprego. A valorização de uma cultura individualista e empreendedora disseminada pela mídia, governos e intelectuais invadiu a vida dos trabalhadores.

Como afirma Silva (2002, p. 101) o par "empregabilidade/empreendedorismo aponta para novos modos de exploração capitalista, cuja característica mais fundamental é a individualização, aliada à subjetivação dos controles que organizam a vida material." A 'flexibilização' das relações de trabalho incentiva a individualidade, recomenda que o indivíduo deva munir de um conjunto de atributos subjetivos para se adaptar às mudanças do sistema produtivo, tais como: capacidade de iniciativa, comunicação, disponibilidade para a inovação e mudança, assimilação de novos valores de qualidade, produtividade e competitividade, no sentido de formar o indivíduo empreendedor ("os empreendedores são pessoas que, com muito pouco ou mesmo a partir do nada, conseguem realizar planos ambiciosos" ${ }^{12}$ ), apto a aprender as habilidades necessárias e se adaptar a novas situações para ter empregabilidade ${ }^{13}$.

É a "nova" cultura do trabalho, como dito anteriormente, apoiada na 'flexibilização' e na exigência da multifuncionalidade do trabalhador para ser competitivo e ter autonomia profissional, cujo caminho é o incentivo e a expansão de formas individualistas de trabalho. Conceitos ideológicos que mascaram a destruição dos direitos da grande maioria dos trabalhadores e o mercado como parâmetro das relações sociais. $\mathrm{O}$ resultado advindo desse processo foi, concretamente, o crescimento do desemprego e da precarização do trabalho. A pesquisa realizada por Gonçalves (2004) é ilustrativa quando mostra o caso de bancários que resolveram investir todas as suas economias em negócio próprio. Não é preciso dizer que a maioria fracassou, tendo que recorrer a qualquer tipo de atividade econômica para garantir a sobrevivência. Antunes (2007, p. 16) constata que "se, no passado recente, só marginalmente nossa classe trabalhadora presenciava níveis de informalidade, em 2007 mais de 50\% dela se encontra nessa condição". As formas precárias de trabalho - legais ou ilegais - estão presentes nos principais centros urbanos da 
periferia capitalista e são usadas como parâmetro para assegurar a flexibilização: contratos temporários e subcontratação de serviços de terceiros são parte do crescente fenômeno da "informalização" do trabalho. (THÉBAUD-MONY e DRUCK, 2007).

Nas mãos do capital transnacionalizado está centralizado o monopólio da ciência e da tecnologia e das redes de informação orientadas para controlar a produtividade e liberar mão-de-obra. $\mathrm{O}$ avanço tecnológico e organizacional alcançado contribui para aumentar a produtividade da economia, favorecendo sua acumulação e centralização, tendo o capital investido minimamente em força de trabalho. Na divisão internacional do trabalho, os países imperialistas, por meio das suas empresas multi/transnacionais, deslocam produção e recursos de acordo com os seus interesses de acumulação. A tendência acumulativa do momento é a da especulação financeira, embora já dê sinais de estafa, evidenciada pelo agravamento da crise atual.

O progresso técnico aplicado à forma de acumulação financeira permite a um grupo cada vez mais seleto de capitalistas obter altos ganhos por meio de informações privilegiadas, sem utilizar, em termos absolutos, de mão-de-obra. Por outro lado, o incremento da composição técnica do capital amplia a utilização do trabalho morto e reduz o uso de trabalhadores estáveis, combinado com uma grande massa de trabalhadores informais, como explica Oliveira (2006, p.135).

\begin{abstract}
Avassalada pela Terceira Revolução Industrial, ou molecular-digital, em combinação com o movimento da mundialização do capital, a produtividade do trabalho dá um salto mortal em direção à plenitude do trabalho abstrato. Em sua dupla constituição, as formas concretas e a "essência" abstrata, o consumo das forças de trabalho vivas encontrava obstáculos, a porosidade entre o tempo de trabalho total e o tempo de trabalho da produção. Todo o crescimento da produtividade do trabalho é a luta do capital para encurtar a distância entre essas duas grandezas. Teoricamente, trata-se de transformar todo o tempo de trabalho em trabalho não-pago; parece coisa de feitiçaria, e é o fetiche em sua máxima expressão. Aqui, fundem-se mais-valia absoluta e relativa: na sua forma absoluta, o trabalho informal não produz mais do que uma reposição constante, por produto, do que seria o salário; e o capital usa o trabalhador somente quando necessita dele; na forma relativa, é o avanço da produtividade do trabalho nos setores hard da acumulação molecular digital que permite a utilização do trabalho informal. (Grifo nosso).
\end{abstract}

Esse processo abre espaço para um grupo de trabalhadores informais que dominam a informática e desenvolvem trabalhos em residência, com comunicação em tempo real via internet com a empresa, alargando o leque de alternativas ocupacionais. Amplia-se, em escala nunca dantes vista no desenvolvimento capitalista, um tipo de gestão da produção descentralizada, "flexível", decorrente da acumulação de mais-valia via progresso técnico, direcionada para diminuir os custos da empresa e aumentar a produtividade. E, ao mesmo tempo, cria-se um tipo de "trabalho abstrato virtual" (OLIVEIRA, 2006, p. 138), podendo ser ilustrado no caso do sistema on line dos bancos o oferecimento de serviços por meio da internet 24 horas por dia, sem necessitar do trabalho de funcionários, quando alguém, de dentro de sua casa ou num terminal bancário em qualquer parte do país ou do exterior faz o trabalho por ele.

Observa-se, portanto, que as mudanças operadas no mundo do trabalho por meio da flexibilização mostram que o capitalismo cria novas - e recria antigas - formas de exploração a serviço da acumulação. Na atual conjuntura de crise capitalista - intensificada 
nos anos 1970 até os dias atuais - a diminuição dos custos do trabalho, reforçando as formas de trabalho precário é a 'alternativa' ensejada.

Voltando o nosso olhar para as feiras livres, tendo como objeto a "Feira do Paraguai" de nossa cidade, notamos a convivência de fragmentos de organização sócioeconômica e cultural de várias etapas da história da humanidade, também a materialização de variados tipos de trabalhos em estado precarizado. Tomando o emblemático exemplo da atividade dos vendedores ambulantes e dos barraqueiros de produtos importados do Paraguai, destacamos duas visões diametralmente opostas. Por um lado, a ocupação de ambulante é vista sob um prisma que enxerga na atividade uma precarização das mais degradantes, chegando a uma condição muito próxima à da economia subterrânea, a qual envolve o tráfico de drogas ou correlatos (TAVARES, 2004). Conforme essa ótica, o ambulante só tem a sua força de trabalho para vender e, para sobreviver, não a vende para o capital: "o fato de estarem no circuito do mercado não significa que são trabalhadores do capital" (idem, p. 153) e, portanto, em princípio parece ser um tipo de trabalho que não interessa ao capital, uma vez que não é considerado trabalho produtivo e nem improdutivo $^{14}$. A sua importância está na realização do valor das mercadorias; o ambulante oferece todo tipo de produto. No entanto, se as mercadorias são produtos do capital e a realização delas se faz por meio da circulação, como separar produção e circulação do processo de realização da mais-valia?

Oliveira (2006, p.140) aproxima-se mais da concretude das relações que perpassam esta atividade econômica, ao lembrar que os vendedores ambulantes de refrigerante em qualquer lugar vêem o aumento da produtividade do seu trabalho graças à preocupação das indústrias em produzir segundo a filosofia do modelo Japonês (jus-in-time). A realização do valor das mercadorias e a forma do trabalho dos vendedores são "primitivas"; isto não importa, o que vale é o uso da força de trabalho para garantir o ciclo de reprodução do capital por meio da acumulação "molecular-digital". 15

Outro elemento a ser destacado para analisar as atividades acima elencadas é o tempo de trabalho. Este, na organização do mercado formal pode ser compreendido pelas explicações dadas por MARX (1985), quando analisa a relação que se estabelece entre o capitalista e o trabalhador na compra e venda da força de trabalho.

O valor da força de trabalho, como o de toda mercadoria, é determinado pelo tempo de trabalho necessário à produção, portanto também reprodução, desse artigo específico. (...). Para sua manutenção o indivíduo vivo precisa de certa soma de meios de subsistência. O tempo de trabalho necessário à produção da força de trabalho corresponde, portanto, ao tempo de trabalho necessário à produção desses meios de subsistência ou o valor da força de trabalho é o valor dos meios de subsistência necessários à manutenção do seu possuidor. A força de trabalho só se realiza, no entanto, mediante sua exteriorização, ela só se aciona no trabalho (MARX, 1985, p.141).

Dadas essas condições, no instante em que o trabalhador vende a sua força de trabalho para a sua reprodução, para a sua subsistência, ele também produz trabalho excedente. $\mathrm{O}$ trabalho despendido pelo trabalhador que não cria valor é definido por Marx como tempo de trabalho excedente: mais-trabalho. Essa capacidade de produzir excedente de trabalho é revertida pelos capitalistas a seu favor, pelo controle da força de trabalho aumentando a sua produtividade.

No trabalho informal o tempo despendido pelo trabalhador é determinante para a sua sobrevivência e reprodução. Desse modo, e neste sentido, tem razão Tavares (2004, 
p.109) quando argumenta que, "dadas as condições técnicas menos desenvolvidas que o trabalho se realiza, produzir um quantum suficiente para realizar suas trocas no mercado implica a necessidade de um volume maior" de trabalho. Ou seja, se por alguma razão deixar de trabalhar um dia, terá que produzir dobrado no dia seguinte. Por este raciocínio, o tempo de trabalho não-pago (tempo do não-trabalho do ponto de vista do trabalho assalariado) é apropriado pelo capital no intuito de completar o seu ciclo de reprodução. A expansão desse tipo de trabalho é fruto do aumento do número de desempregados oriundos da atual configuração de crise capitalista, traduzida na recomposição neoliberal, que veio disponibilizar um alto contingente de força de trabalho que, "sobrante", abriu possibilidades para o ressurgimento de formas arcaicas de exploração, tais como empresas familiares, trabalho domiciliar, sem garantias legais, etc., permitindo a extração do sobretrabalho na sua forma absoluta. Portanto, trabalho utilizado indiretamente, pelo capital monopolista, como elemento de extensão do processo de realização do lucro, sem os custos que teria caso tal realização se desse nos parâmetros formais.

O "trabalhador informal" é, portanto, um operário que, uma vez demitido de seu posto no mercado formal de trabalho, passa à condição de "subcontratado". O resultado desta operação, para o capital monopólico, é a elevação da sua taxa de lucro, ao passo que, para o trabalhador (a), é a queda do seu nível de renda.

Nesse sentido, a ocupação de vendedor de produtos industrializados (inclusive piratas: brinquedos, eletro-eletrônicos, etc.) contrabandeados do Paraguai, em barraquinhas (camelôs) trata-se de uma força de trabalho por conta própria ou de empregados sem vínculo. É uma atividade precária, incerta, suscetível ao risco da fiscalização que, em determinadas ocasiões resolve controlar o fluxo de mercadorias, principalmente quando busca proteger os interesses de indústrias nacionais ou do capital monopólico internacional dono de patentes e marcas. São formas de organização do trabalho desenvolvidas pelos sujeitos no intuito de superar as dificuldades de sobrevivência, ao mesmo tempo em que contribuem para a reprodução do capital.

A precarização, longe de quebrar a rede rotineira de acumulação via realização da mercadoria - ou seja, nos moldes tradicionais -, realiza utilizando-se de formas não propriamente capitalistas de trabalho, permitindo dar continuidade ao ciclo cumulativo das relações capitalistas no todo, ou seja, em escala ampliada. Não à-toa a maioria das mercadorias ali vendidas por esses comerciantes são artigos de plataformas produtivas principalmente da China e Taiwan - com mão-de-obra semi-escrava (portanto não capitalista), por empresas que desterritorializam a produção em busca de níveis mais rebaixados de remuneração da força de trabalho.

As relações descritas no cenário aqui evocado estão presentes em qualquer lugar por onde se espraiaram as relações capitalistas, em distintos graus, formas e intensidade. Talvez, não na totalidade dos seus elementos, na pujança, no alcance e em tamanha magnitude com que se mostram na contemporaneidade. Assim, a realização da mais-valia sob as formas adversas concretizadas na "Feira do Paraguai" combina com a forma na qual é produzida, consumando a sanha acumulativa do sistema.

Mirando o atual quadro de acumulação e centralização capitalista, vê-se que ele é deturpado pela invenção "globalizacionista", tipificada nas adequações econômicas das políticas neoliberais, de caráter predominantemente financeiro, sobre a organização do trabalho. O "globalizacionismo" trata-se de uma tendência do discurso ideológico dos intelectuais burgueses, ilustrado pela dissonância entre os estratosféricos números macroeconômicos mundiais e o crescimento real da economia ${ }^{16}$, marcado pelo descompromisso com o bem-estar social. Outra sua característica é a compreensão do todo de forma a dissociar a questão social da econômica, o que nos cobra uma abordagem que 
constitua um elo entre a reestruturação econômico-produtiva e seu vínculo com o ajustamento social.

É nesse sentido que se entende que o cenário evidenciado aponta para uma crise capitalista de múltiplas dimensões: econômica (caracterizada por uma desaceleração no crescimento baseado na tradicional dinâmica de reprodução ampliada ${ }^{17}$ via realização da mercadoria); social, de conflitos intra e interclasses, num processo de profunda concentração/centralização econômica; e política, caracterizada pela recusa interminável contra a submissão estadunidense (e, por extensão, do grande capital transnacionalizado), entendida por alguns como "antiamericanismo", mas que evidencia uma resistência antiimperialista, e, em alguns casos, à própria essência capitalista.

\section{REFERÊNCIAS}

ALVES, A. E. Qualificação e trabalho bancário no contexto da reestruturação produtiva. Vitória da Conquista, BA: Edições UESB, 2005.

ANTUNES, R. Dimensões da precarização estrutural do trabalho. In: DRUCK, G; FRANCO, T.(org). A perda da razão social do trabalho: terceirização e precarização. São Paulo: Boitempo, 2007. p.13-22.

BARAN, Paul. A economia política do desenvolvimento. Coleção Os Economistas, São Paulo: Abril Cultural, 1984.

BORGES, A. Desestruturação do mercado de trabalho e vulnerabilidade social: a região metropolitana de Salvador na década de 90. 2003.354 f. Tese (Doutorado em Ciências Sociais) - FFCH, UFBA, Salvador, BA, 2003.

DIEESE. O rosto dos bancários: mapa de Gênero e Raça do Setor Bancário. 2001. Disponível em: www.dieese.org.br.

EVANGELISTA, J; MACHADO, L. Empregabilidade. In: FIDALGO, F.; MACHADO, L. Dicionário da Educação profissional. Belo Horizonte: NETE, 2000.

FOUGEYROLLAS, Pierre. O tempo histórico das revoluções e a crise da modernidade. In: Estudos, nº 38, São Paulo: FFLCH-USP, 1993.

FRIGOTTO, G. A nova e a velha face da crise do capital e o labirinto dos referenciais teóricos. In: FRIGOTTO, G.; CIAVATTA (Orgs.). Teoria e educação no labirinto do capital. Petrópolis, RJ: Vozes, 1991. p. 21-46.

GALBRAITH, John Kenneth. A era da incerteza. $5^{\text {a }}$ Edição, Pioneira:São Paulo, 1983.

GONÇALVES, Ida, L. Mercado de Trabalho na Amazônia Brasileira: um estudo sobre a demissão voluntária de bancários e reinserção profissional. In: VIII CONGRESSO LUSOAFRO-BRASILEIRO DE CIÊNCIAS SOCIAIS. 2004, Coimbra, PT. Anais...p. 1-14. Disponível em: www.ces.uc.pt.

HARDT, Michael \& NEGRI, Antonio. Império. Rio de Janeiro: Record, 2001.

HARVEY, D. A Condição pós-moderna. Tradução de Adail U.S.; M. ${ }^{a}$ Stela G. 3. ed. São Paulo: Loyola, 1993.

HIRATA, H.; PRETECEILLE, E. Trabalho, exclusão e precarização socioeconômica: o debate das ciências sociais na França. Caderno CRH, Salvador, BA, $n^{\circ}$ 37, p.47-90, jul/dez., 2002

LÊNIN, V. I. O Imperialismo: fase superior do capitalismo. $3^{\mathrm{a}}$ ed. Obras Escolhidas, Tomo I. São Paulo: Alfa-Ômega, 1986.

LENS, Sidney. A fabricação do império americano - da Revolução ao Vietnã: uma história do imperialismo dos Estados Unidos. Rio de Janeiro: Civilização Brasileira, 2006. 
LIMA, Jacob Carlos. Trabalho, informal, autogestionário e gênero. Sociedade e Cultura. n.02, UFG, Goiânia, GO, ano/vol 9, p.303 - 310, Jul/dez, 2006. Disponível em: http://redalyc.uaemex.mx/redalyc/pdf/703/70390204.pdf.

MARX, K. O Capital, livro I, capítulo VI (inédito) Tradução de Eduardo Sucupira Filho. São Paulo: Ciências Humanas, 1978.

MARX, K. O Capital - Crítica da Economia Política. In: Coleção "Os economistas". Tradução de Regis Barbosa e Flávio R. Kothe. 2. ed. São Paulo: Nova Cultural, 1985. v. 1.

PAIVA, V. Inovação tecnológica e qualificação. Educação e Sociedade, São Paulo, ano XVI, n.50, p.70-92, abr. 1995.

PAIVA, V. Qualificação, crise do trabalho assalariado e exclusão social. In: GENTILI, P.; FRIGOTTO, G. (Orgs.). A cidadania negada: políticas de exclusão na educação e no trabalho. Buenos Aires, Argentina: Clacso, 2000.

OLIVEIRA. F. Crítica à razão dualista: o ornitorrinco. São Paulo: Boitempo, 2006.

SADER, Emir et alli (Orgs.). Enciclopédia contemporânea da América Latina e do Caribe. São Paulo: Boitempo, 2006.

SATO, Leny. Processos cotidianos de organização do trabalho na feira livre. Revista Psicologia \& Sociedade, v,19, n.spe , Porto Alegre, RS, 2007. p. 1-12. Disponível em: www.scielo.br.

SENNETT, R. A correção do caráter: consequiências pessoais do trabalho no novo capitalismo. Tradução de Santarrita. M. 2. ed. RJ; SP: Record, 1999.

SILVA, Luiz A. M. Da informalidade à empregabilidade (Reorganizando a dominação no mundo do trabalho). Caderno CRH, Salvador, BA, n,37, p.81-109, jul/dez., 2002.

SWEEZY, Paul M. Teoria do desenvolvimento capitalista: princípios de economia política marxista. Coleção Os Economistas, São Paulo: Abril Cultural, 1983.

TAVARES, M. A. Os fios (in) visíveis da produção capitalista: informalidade $e$ precarização do trabalho. São Paulo: Cortez, 2004.

THÉBAUD-MONY, Annie; DRUCK, Graça. Terceirização: A erosão dos direitos dos trabalhadores na França e no Brasil. In: DRUCK, G; FRANCO, T. A perda da razão social do trabalho: terceirização e precarização. São Paulo: Boitempo, 2007. p. 23-58.

WHEEN, Francis. Como a picaretagem conquistou o mundo: equívocos da modernidade. Rio de Janeiro: Record, 2007.

\footnotetext{
${ }^{1}$ Professora da Universidade Estadual do Sudoeste da Bahia - UESB e pesquisadora do grupo de estudos História, Trabalho e Educação do Museu Pedagógico da UESB.

${ }^{2}$ Professor da Universidade Estadual do Sudoeste da Bahia - UESB, pesquisador do Neils/PUCSP e do Museu Pedagógico da UESB.

3 ZOLA, Émile. Germinal. São Paulo: Círculo do Livro, 1996. p. 197.

${ }^{4}$ Cidade do interior da Bahia.

5 Organização da produção agro-exportadora em larga escala voltada para o mercado externo, utilizando mãode-obra escrava, grandes unidades produtivas (latifúndio) e o regime de monocultura. A aproximação aqui é meio tosca, mas refere-se à manutenção - e reprodução - dos traços gerais do plantation colonizador através do agronegócio. Aliás, este termo constitui elemento do discurso ideológico surgido nos EUA em meados do século XX e difundido na América Latina na década de 1990 com o intuito de formatar uma imagem "moderna" da agricultura capitalista, que já se encontrava desgastada. No agronegócio, a mão-de-obra escrava ou servil foi substituída pela assalariada em condições muito semelhantes ao plantation onde o status jurídico é a diferença palpável. Acerca ver SADER Emir et alli (orgs.). Enciclopédia contemporânea da América Latina e do Caribe. São Paulo, Boitempo, 2006.

6 O processo de produção é entendido aqui sob a ótica marxiana, ou seja, como uma combinação de trabalho e valor, ao passo que a reprodução compreende a produção mais a criação de condições pelas quais ela continue a ocorrer. Em outras palavras, processo empreendido pelo capital determinante de um novo ciclo de produção. A
} 
reprodução pode ser simples (quando o novo ciclo é encetado com o mesmo valor com que iniciou o ciclo anterior), ou ampliada (quando o novo ciclo começa com um valor acima do que iniciou o ciclo anterior).

7 Aumento de valor do capital em toda empresa capitalista em conseqüência da acumulação e da concorrência (eliminação dos capitalistas menores e mais fracos). Na concepção de Lênin (1986), a livre concorrência engendra a concentração da produção que, por sua vez, em certo grau de evolução, conduz ao monopólio.

8 Encontro realizado entre os dias $1^{\circ}$ e 22 de julho de 1944, reunindo 730 delegados de 44 países do mundo então em guerra, em Bretton Woods, no Estado de New Hampshire, EUA. Foi uma espécie de pré-ONU onde se discutiu o que deveria ser a "Nova Ordem Econômica Mundial" no que se referia à questão da estabilidade financeira a nível planetário. O resultado foi a criação dos dois motores da ordem financeira: o FMI e o BM (á época, Banco Internacional de Reconstrução e Desenvolvimento (BIRD)). Conferência que, para Galbraith (1983, p.224), não foi entre nações, mas de nações com Keynes.

9 O quadro de crise em que imergia o capitalismo mundial mostrava certo cansaço do modelo constituído em Bretton Woods. Nos EUA, o déficit do balanço de pagamentos e de investimentos externos, a quantidade de dólares que espalhou pelo mundo para custear suas aventuras militares, a queda nas suas reservas de ouro e o aumento contínuo das suas dívidas, resultaram numa insegurança internacional nos negócios que levou a uma corrida por converter dólares em moedas mais seguras então (o iene, o marco e o franco suíço). Em 1971, Richard Nixon desvalorizou o dólar, dando um grande calote nos investidores internacionais e congelou preços e salários, jogando a crise nas costas dos trabalhadores. Nesse ínterim, as economias japonesa e alemã passaram a competir em pé de igualdade e, em certos setores, superaram a estadunidense (LENS, 2006, p. 628-629).

10 Conjunto de profundas reformas político-econômicas aplicadas nos países periféricos do sistema capitalista, durante a década de 1980, levado a cabo pelo FMI e pelo Banco Mundial, como condicionamento do acesso a novos empréstimos por parte das instituições multilaterais.

11 Assinala-se aqui que o que denominam de "pirataria" faz parte da demanda efetiva global, sendo computada nas estatísticas que registram renda e emprego, representando parte do bem-estar social e possibilidades de crescimento de significativa parcela da população economicamente ativa.

12 Frase do artigo "Como fazer uma empresa de sucesso partindo do nada" Disponível em: www.endeavor.org.br. Acessado em 20/10/2008.

${ }^{13}$ Empregabilidade refere-se às condições subjetivas de inserção e permanência dos sujeitos no mercado de trabalho, e, também, às estratégias de valorização e negociação de sua capacidade. Tem sido ponto de referência de várias políticas educacionais de formação profissional e discursos de empresários "sobretudo, quando centra nos indivíduos, a responsabilidade de sua integração no mercado de trabalho" (idem), relacionando-o ao emprego/desemprego e dispositivos de formação (EVANGELISTA \& MACHADO, 2000, 141). Descolada das instituições formais e da experiência adquirida no trabalho, a empregabilidade dá maior peso aos aspectos pessoais e disposições subjetivas: atitudes e características de personalidade, elementos menos mensuráveis objetivamente (PAIVA, 2000). Observa-se, portanto, que a noção de "empregabilidade" se caracteriza como um conceito que transfere da empresa e do governo a responsabilidade pelo emprego e o desemprego, para os sujeitos individuais.

${ }^{14}$ Para Marx (1978, p. 70-72) trabalho produtivo é aquele que emprega a força de trabalho e diretamente produz mais-valia. É o trabalho consumido diretamente no processo de produção com vistas à valorização do capital, o trabalho que se realiza concretamente em mercadoria. $\mathrm{O}$ trabalho improdutivo é aquele que se compra como valor de uso, como serviço, não como trabalho que gera valor de troca. Na sociedade "molecular -digital" trabalho produtivo e improdutivo se confundem.

15 De acordo com Oliveira (apud Frigotto, 2002, p. 34-35) "a massa de capital fíctício e especulativo configura um movimento de passagem de uma sociedade jurídico-política em direção à sociedade moleculardigital. Este movimento afeta, em última análise, a base fundamental da forma capitalista de relações sociais - a propriedade privada. O processo invisível por excelência é o capital fictício, que viaja em tempo realdigital de um para outro mundo, e viaja em moléculas, que é o próprio dinheiro, não necessitando fixar-se em unidades físicas. Mesmo quando se fixa em unidades industriais, o que preside a ordem desta fixação é o caráter fictício do capital dinheiro, ao contrário da sociedade do conflito, em que o capital-dinheiro só existe depois de construir a força do trabalho vivo. A sociedade da ordem jurídico-política é fundada na propriedade tangível, enquanto na sociedade molecular-digital a regra é o intangível, o invisível". A nosso ver, nessa aparente transição de ordem social centra-se a real contradição do capitalismo que explode na atual crise sistêmica.

16 Aqui entendido o crescimento (ou desenvolvimento) econômico no sentido aludido por Baran (1984:47), que concebe esta categoria como relacionada a um aumento, ao longo do tempo, da produção per capita - para além do sentido burguês do termo atualmente - de bens materiais.

17 No sentido capitalista, este processo é caracterizado pelo crescimento do capital por meio de capitalização progressiva da mais-valia. Marx a expressava como "acumulação de capital" num contexto em que a mais-valia 
já não é consumida totalmente pelos capitalistas, mas dividida entre três esferas, sejam: a parte consumida por estes; a parte que se acrescenta ao capital constante (meios empregados para a produção, constando do capital fixo e circulante: máquinas, imóveis, matérias-primas, mercadorias...); e uma terceira acrescentada ao capital variável (trabalho vivo, calculado como a soma de salários pagos pela exploração da força de trabalho). (Acerca ver SWEEZY, 1983, p.75-76 e 129-151). A reprodução ampliada do capital equivale à capitalização da maisvalia anteriormente realizada. Aqui estas expressões se alternam, mas sem perder de vista este significado.

Artigo recebido em: 20/11/2008

Aprovado para publicação em: 03/12/2008 